\title{
Editorial
}

\section{Readers' views: IDM journal: Survey of readers}

Journal of Direct, Data and Digital Marketing Practice (2010) 11, 265-267. doi:10.1057/dddmp.2010.8

Last autumn, the IDM conducted a survey of readership for the Journal. Peter Mouncey, our resident market-research expert on the Editorial Board, has kindly assessed your responses, and provided the following report which is quoted herewith:

\section{"Methodology}

During October and November 2009, the IDM conducted a survey of readership for the Journal.

The survey was primarily conducted over the Internet, with emails sent to IDM members and students currently studying for the IDM's professional qualifications, inviting recipients to use the imbedded link to access and complete the questionnaire on the IDM website.

"This audience could also follow links reminding them to participate in the survey on IDM emails and the journal pages of the IDM website. A hardcopy of the questionnaire was also despatched with Volume 11 Number 2 to mail back to the IDM. The incentive for taking part was the chance to win a lifetime membership of the IDM.

\section{"Your response}

In total, 255 usable responses were collected, representing an overall response rate of 9.6 per cent of contactable members. This is obviously a relatively small number of overall readers, but the findings have provided some interesting and useful insights into how you feel about the Journal, and will certainly help with developing future strategy. Thank you to all those who took the time to respond, and for those who didn't take part we hope that the findings reflect your views.

\section{"Highlights and editorial response}

So, what do those readers who responded think of the Journal? We have put the data under the microscope, looking at the different sub-samples and other groups, such as age, grade of IDM membership, company size, etc, but we've had to conclude that the findings show a high level of consistency. Here is a flavour of the main findings:

- Respondents thought the papers published in the Journal were useful, or very useful. Generally they thought that the current balance within the different key topics (direct marketing, digital, databases, general articles, case studies, etc) was about right. However, some readers commented that coverage of the digital world was sometimes at the expense of traditional direct marketing, and we will take that view on board in planning the content of future issues. In addition, others said they wanted more international perspectives, and this is also noted.

- Most respondents preferred the content to be sourced from practitioners. Case studies were particularly welcomed, as well as articles or briefings on new technology. This view supports our editorial strategy. We are not seeking to produce an academic journal. We believe that readers need to gain practical value from the content. 
- The preference across all groups was for a hardcopy version, published quarterly as at present. Older readers particularly favoured the printed version, but even among readers aged under 30 , over half preferred this format. Access to content online was welcomed, especially by students, but not as a replacement for a hardcopy version. (However, visitors to the Palgrave website were not specifically invited to participate in the survey, and this group may have a different level of preference for online content.) This finding did surprise us. We had expected a greater preference for online access, but the strategy for the foreseeable future is built around continuing to publish printed copies. However, this does not mean that we will not be looking at ways to use the Internet more effectively.

- Recipients of the Journal tend to keep their copies. This is a very pleasing finding, demonstrating that respondents see a lasting value in the content. It can still be easier to pull a copy off the shelf rather than search online. We will provide an annual printed index to make it easier for readers to find the appropriate copy as quickly as possible.

- Respondents claim to spend around 30-60 minutes on average reading the content of each issue. However, those accessing the Journal online (eg IDM Affiliate Students) tend to spend less time reading the Journal than those receiving printed copies. Also, those mailing their completed questionnaires appeared to spend a bit longer reading it than those responding online (the majority of respondents). We don't expect readers to read each issue from cover to cover, but this length of average readership suggests that many readers take the time to explore the content of each issue, and perhaps read one article in full.

- Respondents tend to keep their copies to themselves, rather than share them with their colleagues, although they do recommend the Journal to colleagues from time to time. We would like those receiving the Journal to share each issue with their colleagues. They may find something of immediate value, or know that it is worth consulting when they need help. Circulating copies in this way might also encourage others to subscribe, or join the IDM and gain the wider benefits of membership. Something for us, and recipients of the Journal, to think about.

- IDM members feel that the Journal is a valued benefit of membership. We believe that the Journal represents a quarterly tangible reminder of the IDM and its value to members, and it was pleasing to see this reflected in the findings.

- Respondents didn't seem to read other journals that might be seen as competitors, or as complementing the Journal. It was very favourably rated compared to other marketing-related magazines that readers read. This confirmed in our minds that the content of the Journal is valued by readers and IDM members.

\section{"Next steps}

As you can see, the findings tended to provide a vote of confidence in the current strategy for the Journal. This does not mean that we are complacent about the future. The findings do provide some pointers as to where we might improve the content, or encourage a wider readership, and we continually ensure that the content is readily accessible digitally as well as in printed form."

Editing a journal does tend to seem like attempting the impossible task of trying to please all of the people all of the time. Of course we know we can't do that, so we will not be unhappy if we manage to please most of our readers some of the time - if not with every article, then with something at least in each issue. But if we fall short of your expectations (or indeed if we (over)fulfil them), you don't have to wait for our next survey to tell us so. Our website is now ready to accommodate your comments on each and every article, and we will be delighted to hear from you, there or by whatever other means you choose.

Meanwhile, we are ending Volume 11 with a full issue: an Opinion Piece from across the Atlantic followed by a paper on the merits of employing happy staff, one on the frequency of 
interactive TV ads, and a third on ways in which government, central and local, is adapting to the digital age - and how marketers in the private sector can learn from this. We have a Case Study from the banking sector, and a New Technology Briefing on speech analytics. Following the usual Abstracts, we have an Index for the major contents of Volume 11 as a whole.

As promised we are giving all IDM members the opportunity to vote this spring for the 'best' article in Volume 11 of the Journal. All members will be invited to vote online, and instructions on how to do so will be forthcoming shortly.

And please don't forget that on our website you have the facility to search by author, title, and keywords across the whole 11 years of the Journal. 